\title{
Continuation of Angiotensin Converting Enzyme Inhibitors in Acute Heart Failure
}

\author{
Waleed AlHabeeb (D) \\ Ahmad Hayajneh (D) ${ }^{2}$ \\ 'Cardiac Sciences Department, King Saud \\ University, Riyadh, Saudi Arabia; ${ }^{2}$ King \\ Fahad Cardiac Center, King Saud Saud \\ University Medical City, Riyadh, Saudi \\ Arabia
}

Purpose: The aim of this study was to show whether blocking the deleterious effects of neurohormonal activation from furosemide by the use of ACEI/ARBs, or the improvement of renal perfusion by using these drugs allows better diuresis and renal function preservation. Patients and Methods: This is a prospective, randomized study in which patients with chronic heart failure were included. Patients admitted for ACEI/ARBs maintenance with acute decompensated HF were added in the study. The patients were divided into two groups: group 1 had ACEI/ARBs continued during admission and group 2 had stopped taking them. Patients with acute heart failure were provided with angiotensin II receptor blockers. Therefore, the present study aims to differentiate between the uses of ACEI/ARBs blocking the deleterious effects of neurohormonal activation or the improvement of renal perfusion by holding these drugs to allow better diuresis and renal function preservation in a young population.

Results: The results showed that the mean age of 32 patients of group 1 was $58 \pm 15.3$ and for group $256 \pm 15.6$. On day of analysis, BP was 113/65 $\pm 11.9 / 6.5$ and 108/66.9 $\pm 14.1 / 9.8$, weight was $68.4 \pm 19.8 \mathrm{~kg}$ and $73.7 \pm 20.2 \mathrm{~kg}$, net volume balance of urine output was 2810.3 $\pm 1011.8 \mathrm{~mL}$ and $3941.7 \pm 2849.7 \mathrm{~mL}$, and length of stay was $11.75 \pm 6$ and $7.9 \pm 3.7$ days for groups 1 and 2, respectively. There was no significant difference in SBP $(p=0.2926)$, DBP ( $p=0.7369)$, weight $(p=0.4798)$, glomerular filtration rate $(\mathrm{GFR})(p=0.7)$, and volume balance $(p=0.166)$. However, there was statistically significant difference in length of hospital stay $(p=0.0392)$.

Conclusion: The study concluded that continuing ACEI/ARBs or holding them during IV diuresis had no difference in the effect on kidney function or diuresis. Length of stay appears to be shorter for those who held their ACEI/ARBs.

Keywords: acute heart failure syndrome, blood pressure, glomerular filtration rate, length of stay

\section{Introduction}

Acute heart failure syndrome (AHFS) is one of the most prevalent diagnoses among patients that may lead to medical care at hospital. Treating AHFS is an intricate process that is characterized with the diverse population of affected patients, lack of a widely accepted description, inadequate consideration the pathogenesis and insufficient evidenced-based instructions. ${ }^{1}$ The primary management goal in these patients is relief of congestion and the improvement of symptoms. Management of intravenous loop diuretics is effective in decreasing elevated venous filling pressures and remains the first-line treatment of volume overload and congestion. ${ }^{2}$ Patients admitted with evidence of significant fluid overload should initially be
Correspondence: Waleed AlHabee Tel +966555466593

Email walhabeeb@ksu.edu.sa 
treated with loop diuretics that are usually given intravenously. Early intervention brings about useful results for patients hospitalized with decompensated $\mathrm{HF}^{3}{ }^{3}$

The acute use of furosemide for diuresis has been shown to stimulate the production of renin. This further increases levels of angiotensin-vasopressin with initial elevation in filling pressures, especially in the first 20-30 min, before the suspected effect of volume depletion by diuresis. ${ }^{4}$ Soon after administration, cardiac function is depressed, but filling pressures fall and stroke volume increases, as diuresis occurs. ${ }^{5}$ The neurohormonal effects return to baseline levels with longer use.

Substantial evidence has accumulated to indicate that angiotensin-converting enzyme inhibitor (ACEI) antagonism of the renin-angiotensin-aldosterone system (RAAS) decreases morbidity and mortality across multiple cohorts of patients with left ventricular (LV) dysfunction. ${ }^{6}$ ACEIs are considered as cornerstone treatment in chronic heart failure secondary to left ventricular dysfunction. This treatment should be prescribed to all patients with heart failure (HF) due to left ventricular (LV) systolic dysfunction with reduced left ventricular ejection fraction (LVEF), unless the patient has a contraindication to their use or have been shown to be unable to tolerate treatment with these drugs. $^{7}$

Angiotensin II helps to maintain adequate glomerular filtration when renal perfusion pressure is low by constricting the efferent arteriole. Consequently, inhibition of ACE can induce renal insufficiency in patients with heart failure. ACE inhibitors reduce glomerular capillary pressure by dilating renal efferent arterioles. ${ }^{8}$ Angiotensin II receptor blockers (ARBs) would exert the same effect by virtue of similar final mechanism.

Optimal diuresis depends on adequate kidney function and perfusion. However, it is unknown whether the combination of furosemide and ACEIs adversely affect the desired response and patient improvement, compared to the use of diuretics alone. Inadequate renal perfusion is not the entire explanation behind worsening renal function in acute heart failure. ${ }^{5}$ There have been some previous studies that showed diuretics are beneficial for acute HF patients, have RAS activation, and that ACEI are not bad for patients on Lasix ${ }^{\circledR}$ (furosimide). ${ }^{9,10}$ However, these studies were conducted on an older adult population, whereas, this study will target young adults. ${ }^{9,10}$ Therefore, the present study aims to differentiate between the use of ACEI/ARBs blocking the deleterious effects of neurohormonal activation or the improvement of renal perfusion by holding these drugs to allow better diuresis and renal function preservation in a young population.

\section{Patients and Methods Study Setting and Participants}

Patients with chronic heart failure on maintenance ACEI/ ARBs admitted with acute decompensated HF and with stable blood pressure were enrolled. A simple random sampling process was used to assign patients to one of the two groups. Several parameters have been analyzed in this study; one of them is the length of stay. The study needs to include 16 patients in each group to achieve a significant reduction of about $40 \%$ in the length of stay, with type I error rate of $5 \%$ and power $80 \%$. Patients who provide written informed consent to participate in the study were assigned to either group 1 or group 2;

- Group 1 continued ACEI/ARBs during admission

- Group 2 had stopped taking ACEI/ARBs

The study was approved by the IRB of King Faisal Specialist Hospital and Research Centre in Riyadh, Saudi Arabia. The patients were evaluated on admission and on day 4 and the results were compared. However, the total duration of the patients' participation in the study was 30 days as they were followed-up for investigating readmission.

\section{Inclusion and Exclusion Criteria}

The inclusion criteria for the study were;

- Men and women $\geq 18$ years

- Patients with chronic heart failure on maintenance ACEI/ARBs admitted with acute decompensated HF

- $\mathrm{BP}$ defined as $\mathrm{SBP} \geq 85 \mathrm{mmHg}$.

- Signed written informed consent obtained prior to inclusion in the study

Whereas, the exclusion criteria of the study were;

- Patients presenting with acute myocardial infarction

- Systolic BP below 85

- Patients with renal transplant or only has one functioning kidney

- Known severe renal impairment (creatinine clearance $<30 \mathrm{~mL} / \mathrm{min}$ ) 
- Administration of any other investigational drug within 30 days before inclusion

- Presence of any severe medical or psychological condition that indicate that participation in the study is not in the best interest of the patient

- Pregnant or breastfeeding women

\section{Study Analysis}

The study analysis was done using the commercial software SPSS program version 17. Comparison between the median levels of creatine, weight loss, and urine output were performed using two sample $t$-test. For dependent observation, the paired sample $t$-test was used. Categorical outcome was analyzed and compared using the Pearson's chi-squared test. Type I error rate was set at 5\%. The statistical analysis of data was done by using the software package SAS version 9.3 (Statistical Analysis System, SAS Institute Inc., Cary, NC, USA). Descriptive statistics for the continuous variables were reported as mean \pm standard deviation and categorical variables were summarized as frequencies and percentages. Continuous variables in the two groups of the study were compared by Student's independent $t$-test; while, categorical variables were compared by chi-squared test. The level of statistical significance is set at $p<0.05$.

\section{Results}

A total of 32 patients admitted with acute decompensated heart failure were evaluated in the present study among which $56.25 \%$ were male. There was no significant difference in gender, ethnicity and past medical history in both groups. The demographics of the patients can be seen in Table 1.

The mean age \pm SD for groups 1 and 2 were $58 \pm 15.3$ and $56 \pm 15.6$, mean $\mathrm{BP} \pm \mathrm{SD}$ was $123 / 71 \pm 14 / 13$ and $120 / 71$ $\pm 18 / 14$, and weight \pm SD was $75.3 \pm 20.8$ and $78.5 \pm 19.8$, respectively (Table 1 ). Baseline mean GFR for groups 1 and 2 were $54.8 \pm 8.3$ and $52.4 \pm 10.9$, respectively. On day of analysis, BP was 113/65 $\pm 11.9 / 6.5$ and $108 / 66.9 \pm 14.1 /$ 9.8, weight was $68.4 \pm 19.8 \mathrm{~kg}$ and $73.7 \pm 20.2 \mathrm{~kg}$, net volume balance of urine output was $2810.3 \pm 1011.8 \mathrm{~mL}$ and $3941.7 \pm 2849.7 \mathrm{~mL}$, and length of stay was $11.75 \pm 6$ and 7.9 \pm 3.7 days, for groups 1 and 2, respectively. The 30day readmission rate was $12.5 \%$ and $18.8 \%$ respectively; while, the 90 -day readmission rate was $25 \%$ and $37.5 \%$, respectively. There was no significant difference in outcome SBP $(p=0.2926)$ and DBP $(p=0.7369)$, weight $(p=0.4798)$, GFR $(p=0.7)$, net volume balance $(p=0.166)$ at $30(p=0.5)$ and 90 -day $(p=0.446)$ readmission rates. The
Table I Patient Demographics

\begin{tabular}{|l|l|l|l|}
\hline Characteristic & N (\%) & N (\%) & p-value \\
\hline $\begin{array}{l}\text { Gender } \\
\text { Male }\end{array}$ & $10(31.25)$ & $8(25.0)$ & 0.374 \\
Female & $6(18.75)$ & $8(25.0)$ & \\
\hline Ethnicity & & & \\
Saudi & $10(31.25)$ & $11(34.37)$ & 0.182 \\
Non-Saudi & $6(18.75)$ & $5(15.62)$ & \\
\hline Past Medical History & & & \\
Smoking & $4(12.5)$ & $5(15.62)$ & 0.524 \\
Stroke & $1(3.125)$ & $0(0.0)$ & \\
Renal insufficiency & $3(9.37)$ & $4(12.5)$ & \\
PVD & $2(6.25)$ & $3(9.37)$ & \\
ICD & $2(6.25)$ & $3(9.37)$ & \\
Hypertension & $12(37.5)$ & $14(43.75)$ & \\
Hyperlipidemia & $8(25.0)$ & $6(18.75)$ & \\
Diabetes mellitus (non- & $2(6.25)$ & $2(6.25)$ & \\
insulin treated) & & & \\
Diabetes mellitus (insulin & $3(9.37)$ & $1(3.125)$ & \\
treated) & & & \\
Atrial fibrillation or flutter & $3(9.37)$ & $4(12.5)$ & \\
\hline
\end{tabular}

only statistically different outcome was observed for length of stay (LOS) ( $p=0.0392)$ (Table 2).

This study addresses a common daily question that one experience while managing patients admitted with decompensated HF. There are lots of data in management of chronic heart failure patients but no significant change in acute heart failure management has been shown in the past two decades. ${ }^{11}$ Therefore, loop diuretics are still the main treatment for patients presenting with ADHF. One of the main limiting factors in continuing or dose adjustment of diuretics is kidney function, which is more complicated than just the effect of diuresis itself including kidney handling, cardiac output, and organ perfusion. The relationship between worsening renal function and poor outcomes in patients with heart failure has been established; ${ }^{12}$ although, some

Table 2 Baseline Characteristics

\begin{tabular}{|l|l|l|l|}
\hline Characteristic & $\begin{array}{l}\text { Group I } \\
\text { Mean (士SD) }\end{array}$ & $\begin{array}{l}\text { Group 2 } \\
\text { Mean (士SD) }\end{array}$ & p-value \\
\hline Age & $58.6(15.3)$ & $56.1(15.6)$ & 0.6503 \\
Weight & $75.3(20.8)$ & $78.5(19.8)$ & 0.6609 \\
Heart rate & $91.1(25.2)$ & $90.7(15.8)$ & 0.9535 \\
Systolic blood pressure & $123.4(14.7)$ & $120.5(18.2)$ & 0.6187 \\
Diastolic blood pressure & $71.8(13.1)$ & $71.4(14.1)$ & 0.9281 \\
Creatinine & $97.1(35.1)$ & $107.6(14.1)$ & 0.4223 \\
Creatinine clearance & $54.8(8.3)$ & $52.4(10.9)$ & 0.5038 \\
\hline
\end{tabular}


uncertainty about the importance of transient worsening persists. ${ }^{13}$ According to some studies, this worsening of renal function is caused by hemodynamic abnormalities and therapy with diuretics. ${ }^{14,15}$ Also, most of the patients with acute HF also have decreased glomerular filtration rate causing renal insufficiency, which further causes decreased renal function in a cardiac event. ${ }^{14}$

Beta-blocker use and hold has been discussed on several occasions during decompensation; ${ }^{16}$ however, it is not observed which is the class I standard therapy in heart failure with systolic dysfunction. Diuretics greatly assist patients with low cardiac output, with increased GFR seen shortly after (few hours to next day) due to increased renal perfusion. In acute $\mathrm{HF}$ with reduced $\mathrm{CO}$, usage is beneficial. ${ }^{17}$ The ACC/AHA guidelines state that patients admitted with significant worsening of renal function should be considered for reduction in or temporary discontinuation of ACE inhibitors, ARBs, and aldosterone antagonists until renal function improves. ${ }^{17}$ The results of this study are novel as the population considered in this study is young, compared to the world data of acute heart failure. However, the patients still had some mild renal impairment that had not worsened with therapy, and was consistent in both groups.

There were some limitations of the study such as, the sample size was small. Also, the history of medications used by the participants and their interactions with the usage and withholding of ACEI/ARBS were not considered. Similar study on bigger sample size and with consideration of other medications is recommended.

\section{Conclusion}

The present study retains the dilemma and puts more pressure on on-site judgment; although it comfortably shows no difference in both strategies. The study showed no difference in blood pressure between the groups, either with or without therapy. One of the main drawbacks of withholding ACEI/ARBs is the interruption of treatment and the high chance of missing reinstitution on discharge. Length of stay is still an important outcome measure as it affects cost and could be a strong determining factor in the choice between the two approaches. It is not clear why LOS was different between the groups; although all other major factors were equivalent. Therefore, future studies need to observe these variables, along with its effects. Rehospitalization was numerically greater in those who had their ACEI/ARBs stopped but did not reach statistical significance, mostly because of the small sample size. At the same time these patients had shorter lengths of stay. There have been variable reports on the length of stay among different world registries.

\section{Ethical Statement}

This study was conducted in accordance with the Declaration of Helsinki.

\section{Acknowledgment}

The authors are very thankful to all the associated personnel in any reference that contributed in/for the purpose of this research.

\section{Disclosure}

The authors report no conflicts of interest in this work.

\section{References}

1. Gheorghiade M, Pang PS. Acute heart failure syndromes. J Am Coll Cardiol. 2009;53:557-573. doi:10.1016/j.jacc.2008.10.041

2. Shin JT, Dec GW. Ultrafiltration should not replace diuretics for the initial treatment of acute decompensated heart failure. Circ Heart Fail. 2009;2:505-511. doi:10.1161/circheartfailure.109.862474

3. Jessup M, Abraham WT, Casey DE; 2009 Writing Group to Review New Evidence and Update the 2005 Guideline for the Management of Patients with Chronic Heart Failure Writing on Behalf of the 2005 Heart Failure Writing Committee. 2009 focused update: ACCF/AHA guidelines for the diagnosis and management of heart failure in adults: a report of the American College of Cardiology Foundation/ American Heart Association Task Force on Practice Guidelines: developed in collaboration with the International Society for Heart and Lung Transplantation. Circulation. 2009;119:1977-2016. doi:10.1161/CIRCULATIONAHA.109.192064

4. Francis GS, Siegel RM, Goldsmith SR, et al. Acute vasoconstrictor response to intravenous furosemide in patients with chronic congestive heart failure: activation of the neurohumoral axis. Ann Intern Med. 1985;103:1-6. doi:10.7326/0003-4819-103-1-1

5. Francis G. Acute decompensated heart failure: the cardiorenal syndrome. Ann Intern Med. 2006;73:S8.

6. Mielniczuk L, Stevenson LW. Angiotensin-converting enzyme inhibitors and angiotensin II type I receptor blockers in the management of congestive heart failure patients: what have we learned from recent clinical trials? Curr Opin Cardiol. 2005;(4):529-534. doi:10.1097/01. hco.0000167721.22453.9c

7. Hunt SA. ACC/AHA 2005 guideline update for the diagnosis and management of chronic heart failure in the adult: a report of the American College of Cardiology/American Heart Association Task Force on Practice Guidelines (Writing Committee to Update the 2001 Guidelines for the Evaluation and Management of Heart Failure). JACC CardioOncol. 2005;46:e1-82. doi:10.1016/j.jacc.2005.08.022

8. Goodman LS. Goodman and Gilman's manual of pharmacology and therapeutics. Mcgraw Hill Professional; 2008.

9. Mentz RJ, Stevens SR, DeVore AD, et al. Decongestion strategies and renin-angiotensin-aldosterone system activation in acute heart failure. JACC Heart Fail. 2015;3:97-107. doi:10.1016/j.jchf.2014. 09.003

10. Davies MK, Gibbs CR, Lip GY. Management: diuretics, ACE inhibitors, and nitrates. BMJ. 2000;320:428-431. doi:10.1136/bmj.320. 7232.428 
11. Metra M, Cotter G, Gheorghiade M, et al. The role of the kidney in heart failure. Eur Heart J. 2012;33:1242-2135. doi:10.1093/eurheartj/ehs205

12. Damman K, Navis G, Voors AA, et al. Worsening renal function and prognosis in heart failure: systematic review and meta-analysis. J Card Fail. 2007;13:599-608. doi:10.1016/j.cardfail.2007.04.008

13. Felker GM, Lee KL, Bull DA, et al. Diuretic strategies in patients with acute decompensated heart failure. $N$ Engl J Med. 2011;364:797-805. doi:10.1056/nejmoa1005419

14. Ruggenenti P, Remuzzi G. Worsening kidney function in decompensated heart failure: treat the heart, don't mind the kidney. Eur Heart J. 2011;32:2476-2478. doi:10.1093/eurheartj/ehr242
15. Ronco C, Bellasi A, Di Lullo L. Implication of acute kidney injury in heart failure. Heart Fail Clin. 2019;15:463-476. doi:10.1016/j. hfc.2019.05.002

16. Metra M, Torp-Pedersen C, Cleland JG, et al. Should beta-blocker therapy be reduced or withdrawn after an episode of decompensated heart failure? Results from COMET. Eur $J$ Heart Failure. 2007;9:901-909. doi:10.1016/j.ejheart.2007.05.011

17. Yancy CW, Jessup M, Bozkurt B, et al. 2013 ACCF/AHA guideline for the management of heart failure: executive summary: a report of the American College of Cardiology Foundation/American Heart Association Task Force on practice guidelines. Circulation. 2013;128:1810-1852. doi:10.1161/cir.0b013e31829e8807

\section{Publish your work in this journal}

The International Journal of General Medicine is an international, peer-reviewed open-access journal that focuses on general and internal medicine, pathogenesis, epidemiology, diagnosis, monitoring and treatment protocols. The journal is characterized by the rapid reporting of reviews, original research and clinical studies across all disease areas. The manuscript management system is completely online and includes a very quick and fair peer-review system, which is all easy to use. Visit http://www.dovepress.com/ testimonials.php to read real quotes from published authors.

Submit your manuscript here: https://www.dovepress.com/international-journal-of-general-medicine-journal 